\title{
Direitos humanos e diversidade cultural $^{*}$
}

\author{
Eduardo Kroeff Machado Carrion ${ }^{\star \star}$
}

Minha exposição tem por objeto Direitos Humanos e Diversidade Cultural. Entretanto, a reflexão sobre esse tema deve inserir-se, tal como definido pela coordenação do projeto Tribunos da Cidadania, em um contexto mais abrangente, que diz respeito a Preconceito e Tolerância e também à Igualdade e Celebração da Diferença. Assim, não tratarei imediatamente do ponto especifico. Retomarei antes algumas observações sobre o conceito de igualdade e a problemática da diferença. A começar, o conceito de igualdade.

\section{IGUALDADE E DIFERENÇA ${ }^{1}$}

Com razão, atribuímos geralmente um valor positivo à idéia de igualdade. Opõe-se ela à discriminação, opõe-se ao preconceito, opõe-se mesmo à violência. Opõe-se mesmo à violência porque, exatamente, a discriminação, o preconceito, a desigualdade fomentam a violência. Nesse sentido, a idéia de igualdade opõe-se também à violência, não só à discriminação e ao preconceito. Mais ainda: geralmente, no pensamento clássico, a idéia de justiça significa,

\footnotetext{
* O presente texto resulta de palestra proferida para a EDHUCA - Escola de Direitos Humanos e Cidadania, dentro do projeto Tribunos da Cidadania da Faculdade de Direito da UFPel em convênio com a Secretaria de Estado dos Direitos Humanos, do Ministério da Justiça, com o apoio institucional da UNESCO, Pelotas, 10/11/2001. Mantive o estilo coloquial originário.

** Ex-diretor e professor titular de Direito Constitucional da Faculdade de Direito da UFRGS. 1 Retomo aqui alguns pontos tratados em trabalho anterior: (CARRION, Eduardo Kroeff. Igualdade, preconceito e violência. In: adquiridos e outros estudos. Porto Alegre: Síntese, 2000. Reforma constitucional e direitos
} 
substancial ou fundamentalmente também, a de igualdade. Justiça como igualdade. Assim, a idéia de igualdade adquiriu um sentido significativamente positivo na nossa cultura. Entretanto, muitas vezes ela representou ou ainda representa um valor claramente negativo. Já na Grécia Antiga, encontramos um discurso em defesa da desigualdade. Em um dos diálogos de Platão, um dos personagens, Cálicles, expressa basicamente o seguinte: a idéia de igualdade é a bandeira dos fracos que querem com a lei conter os fortes. Temos aqui a idéia de igualdade como algo essencialmente negativo porque não possibilita que os fortes sejam fortes e não ajuda a que os fracos continuem fracos. Temos aqui um discurso extremamente preconceituoso e conservador. Seria uma espécie de "darwinismo social". Darwin falou em seleção natural, a evolução das espécies dependendo de uma seleção natural. Importar a idéia de seleção natural para o mundo social, para a esfera da convivência entre pessoas humanas, torna-se extremamente preconceituoso e conservador. Significa em última análise afirmar que os fortes devem sempre se sobrepor aos fracos porque os fortes são fortes e os fracos são fracos. Essa proposta, portanto, já encontramos expressa em um dos diálogos de Platão, que utiliza o personagem para expor um tipo de discurso disseminado na época, um discurso conservador e preconceituoso, de defesa da desigualdade e de crítica à idéia de igualdade, concluindo finalmente que a desigualdade seria natural e a igualdade, artificial. Em outros termos, a lei seria artificial porque pretenderia transtornar a relação natural entre fortes e fracos. Vemos aqui uma crítica à idéia de igualdade. É também o discurso do neoliberalismo que já está presente nesse personagem de um dos diálogos de Platão, Cálicles. Nesse sentido, não há nenhuma novidade no neoliberalismo. O neoliberalismo é finalmente um discurso requentado das elites, dos discursos das elites que já vêm desde a Antigüidade, passando por esse personagem de um dos diálogos de Platão chamado Cálicles. Vemos, assim, a crítica à idéia de igualdade. Uma crítica conservadora à idéia de igualdade. Podemos também formular uma crítica à idéia de igualdade numa outra perspectiva. Referi-me, inicialmente, ao aspecto positivo da idéia de igualdade para depois mostrar a crítica conservadora à idéia de igualdade. Mas podemos também articular uma crítica progressista à idéia de igualdade. Uma crítica progressista da idéia de igualdade na perspectiva da ampliação do processo civilizatório e da construção do futuro. Aqui, tratar-se-á da crítica à mera e simples igualdade formal e da defesa de algo mais, algo além da igualdade formal, que seria a igualdade material. Tratar-se-á finalmente do discurso que surge ou em grande parte se concretiza com o chamado Estado Social, após a $1^{\mathrm{a}}$ Guerra Mundial e sobretudo após a $2^{\mathrm{a}}$ Guerra Mundial. Estado Social esse marcado pela 
implementação e pela efetivação de políticas sociais caracterizadas como políticas compensatórias, de abrandamento das desigualdades materiais. Reconheceu-se que não bastava juridicamente afirmar ou simplesmente afirmar num texto constitucional ou na legislação infraconstitucional que todos eram iguais em direitos, sendo ainda necessário encontrar os instrumentos para a organização e a efetivação dessa igualdade. Reconheceu-se, por exemplo, que não bastava simplesmente atribuir a igualdade formal do direito de voto ao cidadão se ao mesmo tempo se mantinham e se reproduziam gritantes desigualdades econômicas, sociais, culturais, de tal forma que o voto de alguns se multiplicava e se potencializava, negando ou descaracterizando assim aquela igualdade formal inicialmente afirmada. Daí, a necessidade de o Estado Social implementar políticas sociais que compensem ou abrandem essas desigualdades materiais. Essa crítica à idéia de igualdade no sentido da crítica à mera igualdade formal representa a defesa de um passo a mais na idéia de igualdade. Significa a tentativa de trânsito de uma igualdade meramente formal para uma igualdade efetivamente material. Não diz propriamente respeito a uma crítica global à idéia de igualdade, como no discurso anterior, o discurso do Cálicles ou do neoliberalismo, mas concerne a uma crítica às insuficiências da igualdade formal e à luta por sua complementação ou sua superação como igualdade material.
Entretanto, o discurso da igualdade não pode servir de pretexto ou de justificativa para esquecermo-nos da necessidade do reconhecimento da diferença. Não há incompatibilidade entre igualdade e diferença, isso que gostaria de acentuar. Quando se fala em igualdade e diferença, que não se entenda como sugestão de que eventualmente haja algum problema ou conflito inevitável entre igualdade e diferença. Reconheço que possa haver, por momentos, no discurso da igualdade, não em todo o discurso da igualdade, mas em um certo discurso da igualdade, uma aproximação desse certo discurso da igualdade com a idéia de discriminação e de preconceito. Porque esse certo discurso da igualdade, assim como o discurso da intolerância e do preconceito, pode significar um discurso da intolerância e do preconceito com relação a diferença. Reconheço que se possa equivocadamente entender a igualdade como algo oposto ou contrário à diferença. Então, minha crítica a esse certo discurso da igualdade. Embora me pareça que devamos resgatar a idéia de igualdade, não só a igualdade meramente jurídica e formal, mas também a igualdade real, fazer mesmo a apologia da igualdade, não podemos de forma alguma entender a idéia igualdade como um desconhecimento da diferença. Não só a idéia de igualdade não se opõe à diferença, mas, mais ainda, a idéia de igualdade justifica-se num certo sentido a partir da diferença. Se os indivíduos fossem idênticos não 
se justificaria a idéia de igualdade. Exatamente porque os indivíduos não são idênticos é que se torna pertinente a idéia de igualdade. Então, vejam: a idéia de igualdade é antes de tudo uma decorrência da diferença do que uma contraposição à diferença. Se os indivíduos fossem idênticos não haveria propriamente espaço para a reivindicação da igualdade. Exatamente porque os indivíduos são diferentes torna-se pertinente a idéia de igualdade. Há diferenças de classe, diferenças de cultura, diferenças de etnia, diferenças de gênero, inúmeras diferenças, e, por causa dessas diferenças, torna-se pertinente a idéia de igualdade. Assim, a idéia de igualdade se funda na diferença, para resgatar o que há de rico na diferença e afastar o que há de discriminatório na diferença. A idéia de igualdade não existe se não houver a diferença. Se houvesse apenas identidade, a idéia de igualdade não seria nem pertinente nem razoável. Em outros termos, a idéia de igualdade não se funda em uma presumida identidade entre os indivíduos, mas no fato de sua real diversidade, de sua efetiva diferença.

A diversidade é um motor fundamental da evolução. Os geneticistas, os especialistas em biologia, sobretudo em biologia evolutiva, que estudam a evolução natural, têm cada vez mais chamado a atenção para a importância do chamado polimorfismo genético no processo evolutivo. A evolução natural, ao invés de uniformizadora, tem-se revelado diversificante. Ao invés de unificar, ele tende a diversificar. Em outros termos, o processo evolutivo não é um processo que vá uniformizando as espécies, mas sim diversificando as espécies, enriquecendo a existência e a vida. Polimorfismo genético traduz exatamente isso: expressão que significa muitos, poli, ao contrário de único ou de um. Por um lado, poli, muitos ao invés de único ou de um; por outro, morfismo, de forma; quer dizer, finalmente, multiplicidade de formas. Multiplicidade de formas enriquecedora no processo evolutivo. Temos um meio ambiente diversificado. Se também houver diversificação na evolução das espécies, seguramente existirão melhores condições de responder às pressões e aos desafios de um meio ambiente diversificado. Se o processo evolutivo fosse uniformizador, provavelmente nós não teríamos as mesmas condições de sobrevivência na Terra. Exatamente porque o processo evolutivo revela-se diversificador é que nós sobrevivemos em face de um meio ambiente igualmente diversificado. A diversidade possibilita que a humanidade melhor sobreviva porque possui ela assim condições de dar respostas múltiplas a um meio ambiente diversificado. A inter-relação de espécies, de caracteres e de características distintas é que possibilitou em grande parte à humanidade a sobrevivência e o processo civilizatório, sua permanência e continuidade. Para tal, e simplesmente com relação à evolução 
biológica, o polimorfismo genético procura chamar a atenção. Quando, entretanto, damos o salto da evolução biológica para a evolução cultural, tornase muito mais importante a diversidade e a diferença. Graças à diferença é que nós conseguimos dar respostas múltiplas e, finalmente, eficazes. Hoje, para um mesmo desafio da humanidade, não damos necessariamente uma única e simples resposta. Se fôssemos todos iguais, provavelmente daríamos uma única e simples resposta. Exatamente porque somos diferentes, poderemos dar para um mesmo desafio da humanidade múltiplas respostas, com maior probabilidade de acerto. Seguramente, a probabilidade de acerto numa única e simples resposta é muito menor do que a probabilidade de acerto em múltiplas respostas. Graças à essa diversidade, diversidade de características, diversidade de respostas, é que temos razoavelmente evoluído. Sempre com riscos, com riscos de retrocessos, é verdade. Novamente, as respostas únicas, que procuram dividir a humanidade entre o certo e o errado, são respostas uniformizadoras que colocam em risco a própria trajetória da humanidade. Contra isso, temos de nos rebelar. Encontrar respostas na afirmação da diversidade que é o pressuposto da idéia de igualdade.

Feitas essas considerações iniciais, gostaria de tratar mais pontualmente da problemática dos direitos humanos nesse contexto.

\section{DIREITOS HUMANOS: UNIVERSALISMO $\mathbf{X}$ RELATIVISMO}

De forma sumária, podemos dizer que toda construção dos direitos humanos, direitos humanos universais, que se traduzem nos textos legais e, sobretudo, nos textos constitucionais, expressou em grande parte uma construção do mundo ocidental. É inequívoco isto, embora suas raízes estejam na Antigüidade clássica. A questão dos direitos humanos já surge, de forma precária é verdade, na experiência grega clássica, mas se fortalece com o Estoicismo, corrente filosófica que, em grande parte, preparou a emergência do Cristianismo, onde a problemática da liberdade individual talvez tenha sido explorada e refletida de forma mais enfática. O Estoicismo que foi uma importante corrente filosófica durante o helenismo, não mais na fase áurea da Grécia Antiga, mas em uma fase de expansão da cultura grega. O Estoicismo que em grande parte preparou a revolução cultural representada pelo Cristianismo, que também enfatiza a idéia de liberdade individual. Mas, mais recentemente, no mundo moderno, a base da afirmação dos direitos humanos encontra-se na liberdade religiosa. Daí, a importância também da reforma protestante e da afirmação da liberdade religiosa em alguns estados europeus. Da liberdade religiosa podemos deduzir, por extensão, inúmeras liberdades: a 
liberdade de consciência, a liberdade de cátedra, a liberdade de ensino, a liberdade de comunicação, a liberdade de reunião, a liberdade de manifestação, finalmente até mesmo a liberdade de organização sindical e a liberdade de organização partidária. A liberdade religiosa significou uma importante mudança cultural, quebrando o monopólio do pensamento religioso hegemônico ou predominante. Antes, o pensamento diferente era considerado diabólico e, portanto, imediatamente condenado. Afinal, representava uma crítica à ortodoxia da religião oficial. Então, afirmar a liberdade religiosa nesse contexto representou uma verdadeira revolução intelectual. Significou a quebra do monopólio ideológico por parte da Igreja Católica dominante. Foi também uma afirmação da diversidade. Dela podemos deduzir, como já foi dito, inúmeras liberdades modernas. É o que afirma um grande jurista, Jellinek, para quem a base da afirmação dos direitos humanos modernos foi a liberdade religiosa. A partir daí, tivemos uma longa construção dos direitos humanos, inclusive a tentativa de superar a mera igualdade formal e construir a efetiva igualdade material.

A idéia que nós ocidentais temos da universalidade dos direitos humanos, a idéia que temos de direitos humanos universais é, efetivamente, uma idéia universal? Nossa idéia de universalidade ou o que nós entendemos por direitos humanos universais é a mesma idéia de universalidade ou é o mesmo que entendem por direitos humanos universais outras culturas, como a cultura islâmica ou a cultura africana? Não há finalmente distintas interpretações da idéia de universalidade dos direitos humanos? Não há distintas compreensões do que sejam direitos humanos universais? Esta é uma reflexão que estamos enfrentando não só no campo da antropologia, que é uma ciência que estuda as diversidades culturais, mas também no campo do direito, sem falar em outras áreas. Hoje, observamos o surgimento de declarações africanas dos direitos humanos, declarações asiáticas dos direitos humanos e outras com suas especificidades e suas particularidades. Por exemplo, as cartas africanas dos direitos humanos têm uma compreensão um pouco distinta das cartas ocidentais dos direitos humanos. Há uma certa ênfase, nas cartas africanas dos direitos humanos, nos direitos coletivos em detrimento dos direitos individuais. $\mathrm{Na}$ cultura ocidental, priorizamos sobretudo os direitos individuais em detrimento dos direitos coletivos. Na Grécia Antiga, havia igualmente um reforço da idéia do que nós denominaríamos hoje de direitos coletivos em detrimento dos direitos individuais. Praticamente, não houve na Grécia Antiga uma construção da idéia de direitos individuais. Isto ocorrerá posteriormente, como já foi dito, com o Estoicismo. Mas, na filosofia clássica grega, não há propriamente uma perspectiva de direitos individuais 
e sim de direitos políticos, de direitos coletivos. Temos, assim, compreensões diferentes, diversificadas, da própria idéia do que sejam direitos humanos, presumivelmente universais. Há, assim, o risco de nós, como cultura ocidental, entendermos nossa universalidade como a única universalidade possível e verdadeira. Da mesma forma, entendermos a universalidade dos outros como uma parcialidade. Esse, o risco do etnocentrismo cultural que, no fundo, expressa um eurocentrismo cultural ou um ocidentalcentrismo cultural ou até mesmo um americanocentrismo cultural. Facilmente, compreendemos e avaliamos o outro, o diferente, a partir simplesmente de nossos referenciais e paradigmas, presumidos universais. Assim como no ato amoroso quando, muitas vezes, ao invés de instituir-se como diálogo, transforma-se em monólogo. Quando procuro encontrar no outro a projeção do meu eu. Então, na realidade, estou estabelecendo um diálogo comigo mesmo. Dialogo no outro o que existe de eu no outro e não o que existe de outro no outro, o diálogo transformando-se portanto em monólogo. Temos de subverter essa relação, que é uma relação, em grande parte, egoísta ou solipsística e de não compreensão da diferença. $\mathrm{Na}$ realidade, tenho finalmente de reconhecer no outro o que ele tem de outro e não simplesmente o que ele tem de mim nele. O risco, portanto, de lermos outras culturas a partir dos nossos parâmetros, das nossas características e dos nossos sincronismos sem perceber o que existe de sincronismos, de características e de parâmetros distintos e diversificados nas outras culturas. Quer dizer, ler as outras culturas e suas particularidades e diferenças a partir dos nossos critérios uniformizadores. O mundo ocidental tem de ter a sensibilidade da compreensão das diferenças culturais. Por que refirome sobretudo ao mundo ocidental? Porque é um mundo hegemônico.

Há também e seguramente outro risco, um risco num certo sentido oposto: o de sermos então seduzidos pelo relativismo cultural. Todas as culturas seriam finalmente equivalentes ou iguais. Porque, em sendo diferentes, sem termos possíveis de comparação, todas as culturas seriam equivalentes ou iguais. Posso, porém, em nome da diversidade cultural, justificar processos sociais que são processos sociais extremamente aviltantes, que desconhecem, inclusive, a diferença? Hajam vista, por exemplo, as condições das liberdades públicas em alguns países teocráticos, bem como a condição da mulher. Vejase, da mesma forma, algumas práticas existentes em alguns países africanos como a da infibulação que se caracteriza pela ablação do clitóris e pela sutura dos órgãos genitais femininos, em nome de hábitos religiosos ou culturais. Podemos em nome da diversidade cultural aceitar tais práticas? Podemos, em nome da diversidade cultural, aceitar regimes autocráticos e autoritários? Finalmente, são equivalentes nossas conquistas 
democráticas no mundo ocidental e as conquistas ou atrasos com relação ao processo civilizatório em outros horizontes culturais? Por sermos ocidentais, estamos sempre sujeitos à condenação, já que o mundo ocidental é dominante e dominador, nossas conquistas democráticas tendo o sinal inevitável e necessário da negatividade? Estou fazendo essas interrogações para problematizar. Poderia ter algumas respostas, mas não quero dizer que minha resposta seja a resposta universal ou verdadeira. Penso, entretanto, que temos de reconhecer que há sim um processo civilizatório. $\mathrm{O}$ que ocorreu, circunstancialmente, no mundo ocidental? Aqui, volto à idéia de liberdade religiosa. O mundo ocidental, primeiro do que outros, conseguiu laicizar o poder político, isto é, secularizar o poder político. Alcançou diferenciar poder político e poder religioso. Conseguiu resgatar ou instaurar a idéia de poder civil. Resultou de um processo histórico, propiciado, é verdade, pela superação do feudalismo e a emergência do capitalismo e da grande indústria, que foi a base da construção da sociedade democrática e dos direitos contemporâneos. Que, aliás, não são direitos e não são conquistas que possam ser monopolizadas pelo mundo ocidental. São direitos e conquistas universais. Há outras culturas que, até por interesse do mundo ocidental, ficaram inclusive cristalizadas em uma visão teocrática. $\mathrm{O}$ mundo ocidental, os países hegemônicos, ao conquistarem, por exemplo, o mundo africano ou o mundo oriental, mantiveram no poder oligarquias autoritárias e corruptas. Isso fomentou, até por reação, fundamentalismos religiosos. Ao lado do fundamentalismo radical, que vai se traduzir muitas vezes em terrorismo, temos também um fundamentalismo conservador que, com a colaboração ou a conivência do mundo ocidental, não propiciou uma efetiva democratização dessas sociedades. Ora, o mundo islâmico - estou dando a título de exemplo o mundo islâmico em decorrência dos episódios recentes que estamos presenciando -, o mundo islâmico foi de uma exuberância inquestionável. Durante a Idade Média, talvez não seja temerário dizer, esteve por momentos muito à frente do mundo ocidental. É verdade que na Idade Média, presenciamos, desde o século XII, a eclosão das universidades no mundo ocidental. Mas o mundo islâmico resgatou em grande parte a cultura grega clássica. Os avanços nas áreas da reflexão filosófica, da construção poética, das descobertas científicas foram consideráveis. A partir do século XVI, do século XVII, houve uma certa paralisia. Foi quando começou o colonialismo europeu e ocidental. Depois da $1^{\text {a }}$ Guerra Mundial, houve interesse em manter oligarquias atrasadas e autoritárias em função de interesses geopolíticos e econômicos estratégicos. De qualquer forma, temos de entender as conquistas do mundo ocidental, em termos de liberdades e de 
reconhecimento da diferença, como conquistas da humanidade. Não são conquistas exclusivamente ocidentais. São conquistas do processo civilizatório. Então, reconhecer a diferença não significa, necessariamente, tornar todas as culturas equivalentes ou iguais. Temos de, ao mesmo tempo, reconhecer que há um processo civilizatório. Um processo de construção democrática, de ampliação de horizontes democráticos e de conquistas populares.

Como compatibilizar a idéia de universalidade com a idéia de diversidade? Creio que através da perspectiva de um universalismo plural.

Para concluir, gostaria ainda de acrescentar a seguinte reflexão: em que pese todos esses episódios que presenciamos hoje, se formos fazer a leitura da história, veremos que muitas vezes as sociedades avançam, retrocedem, mas que finalmente progridem. Volto a insistir: há um processo civilizatório. Assim como houve uma evolução biológica, demos um salto para uma evolução cultural extremamente rica e diversificada, muito mais rica e diversificada do que a evolução biológica. Ela, a evolução humana, tem a capacidade da transcendência, entre outras coisas. Pois bem, não há como desacreditar deste potencial do processo civilizatório. Finalizo, lembrando um momento da nossa existência como humanidade. Tentemos imaginar o quadro há mais de dez ou quinze mil anos atrás, quando o homem vivia nas cavernas.
A capacidade tecnológica do homem era mínima, reduzida. O homem não tinha a capacidade de acumular riquezas, produzindo basicamente para o seu sustento diário. Ele vivia a duras penas e com dificuldades. Por isso mesmo, não havia ainda a instituição da escravidão, que só passa a economicamente justificar-se - não estou dizendo a moralmente justificarse - quando o homem consegue produzir além da sua necessidade diária de sobrevivência, quando o homem consegue acumular riquezas. Nesse momento a que me refiro, o homem mal conseguia sobreviver. $O$ avanço tecnológico era mínimo. Homem esse com uma baixa expectativa de vida. Pois bem, esse homem, quando foi ensinar seu companheiro de jornada a como caçar o bisão, foi capaz de deixar registrado nas paredes das grutas de Altamira e tantas outras uma verdadeira obra de arte, numa espécie, por assim dizer, de assalto aos céus, transcendendo seu miserável cotidiano. A capacidade de, numa circunstância extremamente desfavorável, fazer uma obra de arte. Ora, se esse homem teve essa capacidade, não somos nós hoje que vamos desacreditar da utopia e do processo civilizatório.

\section{DISCRIMINAÇÃO POSITIVA}

(RESPOSTA À QUESTÃo)

Com relação à idéia da discriminação positiva, acho que ela resgata em grande parte a perspectiva 
da idéia de igualdade. Quando me referi ao trânsito da igualdade meramente formal para uma igualdade real, emerge ou insere-se a perspectiva da discriminação positiva. $O$ direito moderno, $o$ direito que surge a partir do início ou meados do século passado, tentou ser, em grande parte, um direito compensatório. Veja-se o caso do direito do trabalho. A realidade inicial ou a circunstância originária era a de desigualdade de fato entre patrão e empregado. Se superponho a uma desigualdade de fato uma mera igualdade jurídica, estarei fortalecendo a desigualdade material. Então, o que fez o direito do trabalho? Tentou ser um direito compensatório, de proteção ao empregado com relação ao poder absoluto inicial do empregador. Temos já aí uma discriminação positiva. $\mathrm{Na}$ experiência do direito, desde o início do século passado, ou mesmo o final do século retrasado, a idéia de uma discriminação positiva foi pouco a pouco incorporada na legislação. Mas, mais recentemente, houve passos acentuados nessa perspectiva. Por exemplo, nossa Constituição. Ela prevê uma discriminação positiva para os portadores de deficiência física. Temos aqui, claramente, uma desigualdade física. Então, os portadores de deficiência física são constitucionalmente beneficiados por uma discriminação positiva. A questão torna-se um pouco mais problemática com relação a outras desigualdades, como de gênero ou, em termos de acesso ao ensino, sobretudo o ensino universitário público, entre integrantes de classes abastadas e membros de classes populares. A questão passa então a ser um pouco mais problemática. Parece-me que a discriminação positiva nas hipóteses que envolvem diferenças culturais, num sentido amplo, não tanto físicas, como os portadores de deficiência física, pode justificar-se como instrumento transitório. De qualquer forma, temos de examinar cada hipótese com muito cuidado. Discute-se muito com relação ao ingresso nas universidades públicas. Não sei se medidas compensatórias teriam grandes resultados. Porque a universidade caracteriza-se por ser uma instituição de ensino. É verdade, a escola, desde o ensino fundamental, divide, discrimina. É distinto aprender numa escola pública ou numa escola privada, sobretudo numa escola privada de elite. Numa escola pública, no centro da cidade ou numa escola pública de periferia. Então, desde o ensino fundamental a escola discrimina, em termos de classe. $O$ pobre recebe um ensino mais deficiente, o filho da elite, um ensino mais qualificado. Além disso, o filho da elite terá um contexto familiar muito mais enriquecedor, sob o ponto de vista cultural. Demais, terá melhores condições econômicas de realizar cursos complementares. Estabelece-se assim uma desigualdade gritante na disputa por uma vaga pública no vestibular. Mas até que ponto resolve o problema procurar igualar depois no ingresso ao ensino superior? Será esse 
o caminho? Não criará uma nova discriminação, interna ao ensino superior. Temos seguramente de denunciar essa discriminação, essa diferença que a educação escolar estabelece desde o ensino fundamental, e de criar mecanismos de qualificação da escola pública. Temos, portanto, de examinar com cuidado cada situação. Quotas dentro dos partidos para as mulheres, talvez se justifiquem como medida transitória. Mas não podem ter como resultado uma maior discriminação. Como melhor compensar essa marginalização das mulheres na atividade sindical, na atividade partidária? Não existem soluções prontas e acabadas. Podemos até definir um padrão, mas que talvez não se adapte a todas as situações. Em certos casos, justifica-se plenamente a discriminação positiva. O próprio Supremo Tribunal Federal tem reconhecido isso. Justifica-se muitas vezes uma discriminação positiva, nem que seja provisoriamente.

\section{UNIVERSALISMO PLURAL}

(RESPOSTA À QUESTÃO)

Com relação ao universalismo plural, acho que seria, antes de tudo, a afirmação da universalidade. Quando se afirma a universalidade, independe de acreditarmos ou não em uma natureza humana pronta e acabada, constituída desde os primórdios dos tempos. Numa visão religiosa ou teológica, por exemplo, poderíamos dizer que, desde os primódios dos tempos, o homem é feito à imagem e semelhança de Deus. Em outros termos, partiríamos de uma predefinição da natureza humana, facilmente concluindo pela afirmação da universalidade. Seja a partir desse ponto de vista, seja a partir de um outro ponto de vista, segundo o qual não encontramos uma natureza humana predefinida, mas há de qualquer maneira uma construção histórica da natureza humana, a humanidade constituindo-se, o homem constituindose no processo, em ambos os casos conclui-se pela afirmação da universalidade, pelo reconhecimento de conquistas universais. Ou porque a universalidade corresponde a uma natureza predefinida, ou porque os conteúdos dessa universalidade foram socialmente construídos, historicamente constituídos. Entendo, portanto, que se impõe finalmente a afirmação da universalidade. A verdadeira questão é como estabelecer o diálogo da universalidade com as diversidades e com as parcialidades. Veja-se o caso da infibulação. Na perspectiva de um universalismo plural, plural sim, mas universalismo de toda maneira, não há como valorizar essa prática, que é uma prática de desvalorização da mulher, que é uma prática de mutilação, não podendo ser valorizada em nome da diversidade cultural, por melhor que se procure explicar suas raízes ou razões culturais. Temos de reconhecer, sim, os avanços da cultura ocidental que efetivamente existem, antes de tudo a 
laicização do poder político, a secularização do poder político, distinguindo o que é política do que é religião. A política não é religião, se não vira inquisição, como lembrava Albert Camus. Na política transformada em religião, o adversário político não é simplesmente um adversário político, mas um inimigo da religião, merecendo as penas do inferno. Contra ele, tudo vale, o assassinato, a tortura, não importa. Como se fez aqui, durante o regime autoritário. Não precisa se tratar necessariamente de uma religião clássica ou histórica, pode ser uma religião laica. Tal como a doutrina da segurança nacional durante o regime autoritário. Forma também de entender a política como religião. Isso muitas vezes é reproduzido na vida partidária mesmo em situações democráticas. A visão do certo e do errado. Maneira igualmente de tornar religiosa a atividade política. Isso é muito característico em algumas culturas. Sociedades teocráticas em que não há liberdades públicas efetivas, onde emergem fundamentalismos. As liberdades públicas são sempre um contraponto ao poder, poder econômico, poder social, poder político ou poder ideológico. Para construir a democracia, temos que nos contrapor ao poder em todas suas modalidades. Não vou dizer que nas sociedades teocráticas ocorra o mesmo que na Idade Média no mundo ocidental, mas elas revelam alguns elementos análogos. As práticas atrasadas inserem-se muitas vezes nesse contexto de fundamentalismos religiosos, de autocracias. Assim, não podemos, em nome da diversidade cultural, em nome do respeito à diferença, valorizar tais práticas. Devemos formular a crítica. Como, entretanto, atuar na perspectiva de um universalismo plural? Também não adianta conquistar e impor uma ordem, que será a ordem dos dominadores. Como enfrentar a situação? Creio que o diálogo e a pressão internacionais são importantes. Devemos também saber assimilar o que existe de virtudes e qualidades, de perspectivas diferentes, de potencialidades novas em outras culturas. Veja-se o caso das culturas orientais tão ricas em inúmeros aspectos. Por exemplo, as religiões que predominam no mundo ocidental são muito mais racionais, o que é uma virtude, mas também revela limites; o cristianismo, o catolicismo tem todo um aparato teológico, praticamente uma filosofia teológica. É o racionalismo próprio do mundo ocidental. As religiões do mundo oriental trabalham muito mais a questão da sensibilidade e outras facetas que talvez as religiões do mundo ocidental têm, circunstancialmente, relativizado. Há seguramente muito a aprender. Volto então a insistir na idéia de polimorfismo genético, agora como polimorfismo cultural, como diversidade cultural a colaborar para o processo civilizatório. 